DOI 10.37882/2223-2982.2021.12-2.13

\title{
ИНФОРМАЦИОННО-КОММУНИКАЦИОННЫЕ ТЕХНОЛОГИИ В ОБУЧЕНИИ РУССКОМУ ЯЗЫКУ КАК ИНОСТРАННОМУ
}

\section{INFORMATION AND COMMUNICATION TECHNOLOGIES IN TEACHING RUSSIAN LANGUAGE AS A FOREIGN LANGUAGE}

M. Dyshecheva

A. Toktonyazova

Summary: The article analyzes the educational process of studying the academic discipline, various strategies for the implementation of information and communication technologies and audiovisual means. General guidelines for the educational process for the study of the Russian language for foreigners in the information and communication environment are given, its main components and methods of interaction at various stages of study are analyzed. The experience of teaching an academic discipline using modern technologies is analyzed, examples of various educational strategies are given.

Keywords: peculiarities of teaching academic disciplines, teaching Russian as a foreign language, modern technologies.
Дышечева Марят Мухамедовна

К.n.н., доцент, Майкопский государственный технологический университет dana2000_08@mail.ru

Токтоньязова Аида Эдуардовна

К.п.н., доцент, Майкопский государственный технологический университет mgtu-teacher@mail.ru

Аннотация: В статье анализируется образовательный процесс изучения учебной дисциплины, различные стратегии внедрения информационнокоммуникационных технологий и аудиовизуальных средств. Даются общие ориентиры учебного процесса по изучению русского языка для иностранцев в информационно-коммуникационной среде, анализируются его основные особенности и способы взаимодействия на различных этапах изучения. Проанализирован опыт преподавания учебной дисциплины с использованием современных технологий, приведены примеры различных образовательных стратегий.

Ключевые слова: особенности преподавания учебных дисциплин, обучение русскому языку как иностранному, современные технологии.
$\mathrm{O}$ бучение русскому языку как иностранному направлено на овладение иностранными студентами лексическими, грамматическими и произносительными умениями и навыками с целью формирования в сознании языкового опыта, а также новой системы языковой коммуникации. В тоже время проблема двуязычия и многоязычия в образовательном процессе, по мнению А.В. Лентовской [4], обуславливает процессуальные изменения не только в способах подачи учебного материала для обучающихся, но и в видах учебных взаимодействий между участниками образовательного процесса, в целом.

В связи с требованиями Федерального государственного образовательного стандарта высшего образования по различным направлениям подготовки, осуществляющими формирование универсальной компетенции (УК-4) у выпускников в образовательном процессе: это способность использовать современные методы и технологии деловой коммуникации на государственном и иностранном языках, а также владение языком на достаточном уровне для общения с носителями языка по ряду профессиональных вопросов, актуальной проблемой исследования в педагогической науке на сегодняшний день выступает возможность эффективного внедрения информационно-коммуникационных ресурсов в процесс обучения языковых дисциплин, что, в свою оче- редь, способствует решению задач по формированию коммуникативных и профессиональных навыков обучающихся, выражающихся в практическом овладении иностранным языком для сфер настоящей и будущей своей профессиональной деятельности.

Включение информационно-коммуникационных технологий в образовательный процесс, на сегодняшний день, по мнению К.Г. Пашаевой [5], является важнейшим медиатором организации обучения и направлено, прежде всего, на увеличение степени доступности, эффективного взаимодействия и качества образования в области иностранного языка. В частности, на значительную роль внедрения информационно-коммуникационных ресурсов указывает А.В. Лентовская, обуславливая повышение языковых компетенций у иностранных обучающихся с изменениями традиционных привычных схем профессиональной деятельности преподавателя обучения русскому языку иностранцев на систему новейших профессиональных компетенций, непосредственно включающую в основные подходы к практической составляющей преподавания применение ИКТ технологий [4]. Источником новых знаний, в этом случае, для обучающихся становится сеть Интернет и информационные технологии, реализующие личностный подход и индивидуальный образовательный маршрут, а также создающие благоприятные условия для эффективного усво- 
ения обучающимися нового знания, и способствующие организации в образовательном процессе реальной речевой практики для иностранных студентов.

Для организации эффективного информационно-образовательного пространства для обучения русскому языку как иностранному, вслед за С.С. Хромовым, мы определяем ряд основных компонентов учебного процесса: наличие в свободном доступе виртуального образовательного контента для иностранных студентов на различных внутренних и внешних образовательных ресурсах; наличие возможности организации мобильной обратной связи для обмена информацией между всеми участниками образовательных отношений; возможность получения обучающимися всех видов информационных образовательных услуг; создание и поддержка индивидуализированного обучения в электронной образовательной среде [6].

Информатизация образовательного пространства обращает внимание на профессиональную составляющую компетентности преподавательского состава и детерминирует необходимость комплексной модернизации и совершенствования всех образовательных инструментов, методик и технологий. В связи с этим, исходя из компетентностной подхода в образовании, а также в рамках реализации образовательных стандартов третьего поколения, Д.Е. Добринской определены основные новые качественные образовательные ориентиры для преподавателей русского языка как иностранного, способствующие формированию у обучающихся качественно новых коммуникативных и профессиональных компетенций. В первую очередь, это ориентиры, направленные на организацию и управление системой коммуникативного взаимодействия в информационном образовательном пространстве, а также соответствующие компетенции в области виртуальных образовательных ресурсов и конкретных образовательных и информационных программ для достижения частных образовательных целей и задач в рамках изучения русского языка как иностранного [3]. Эффективное применение информационно-коммуникационных инструментов в образовательном процессе в преподавании русского языка иностранцам направлено на овладение ими произносительными, грамматическими и лексическими умениями и навыками.

К основным ИКТ компетенциям преподавателя русского языка как иностранного В.В. Вязовская относит следующие: владение мультимедийными технологиями, использование графических и офисных программ, владение навыками интернет-технологиями, использование коммуникационных технологий в глобальной сети Интернет (веб-блогов, форумов, чатов, видеоконференций и т.д.) [2]. Поэтому, важным фактором, обеспе- чивающим продуктивный результат применения ИКТ в обучении русскому языку иностранным студентам К.Г. Пашаева определяет целенаправленную разработку и использование преподавателем в учебном процессе такого электронного учебно-методического комплекса дисциплины, который отражал бы уровень и специфику его профессиональной ИКТ компетентности. По мнению авторов такой индивидуальное учебно-методическое обеспечение должно включать в себя образовательные ресурсы для обучающихся и инструменты ИКТ технологий для преподавателя. Таким образом, учебные и методические материалы, включающие в себя систему занятий с использованием ИКТ, критерии оценивания, электронные ссылки на языковые интернет-ресурсы, публикации по проблемам реализации ИКТ в преподавании русского языка как иностранного, дополняются инструментальными программными средствами, совершенствующими профессиональные компетенции использования ИКТ в преподавании дисциплины [5].

В связи с вышесказанным, в образовательном процессе, реализующим ИКТ технологии, мы можем выделить такие формы онлайн-обучения, обеспечивающие учебный процесс по модулям и разделам дисциплины, а также коммуникационное взаимодействие участников образовательного процесса, как сетевые, мультимедийные и case-технологии, позволяющие получать обучающимся учебные материалы, консультации, практические задания для самоконтроля через учебные серверы глобальной сети Интернет или использования электронных учебных пособий на персональном компьютере. При этом, эффективность овладения русским языком для иноязычных студентов обусловлена разнообразием форм обучения в образовательном процессе. В этом случае, занятие по русскому языку для иностранного студента, по К.Г. Пашаевой, представляет собой комплекс образовательных задач, направленных на работу с учебным материалом в следующей последовательности: изучение теоретических положений, самопроверка в форме теста, закрепление с помощью выполнения практического задания и обратная связь с преподавателем посредством электронно-почтовой группы средств обучения для оценки и контроля изученного учебного материала. Актуальность работы с электронной почтой, в данном случае, обуславливается необходимостью реализации продуктивной учебной обратной связи в процессе дистанционного обучения, позволяющей своевременно получать обучающемуся учебные материалы от преподавателя, индивидуальные задания и инструкции, а также обоснованные оценки результатов работы и выполнения контрольных заданий. В связи с этим, К.Г. Пашаева обосновывает внедрение в образовательную среду специальных обучающих программ для самоконтроля обучающихся, построенных на коммуникативных упражнениях в вопросно-ответной форме [5]. 
Для наглядной демонстрации учебного материла и закрепления речевых и грамматических навыков, по Э.Г. Азимову, рекомендуется использовать в образовательном процессе преподавания такие аудиовизуальные средства как видеоуроки, формирующие лингвистические, лексические и речетренировочные компетенции у обучающихся, а также организовывать в синхронном режиме электронные видео-конференции для проведения групповых семинарских занятий и консультаций. Большой потенциал для решения лингводидактических задач, формирования коммуникативной компетенции и повышения мотивации у изучению языку у иностранных студентов Э.Г. Азимов также определяет у программных средств Youtube, с помощью которых возможно просматривать видеоматериалы и принимать участие в их оценки и обсуждении с носителями языка. В качестве практических заданий могут быть предложены, к примеру, озвучивание видеоматериала и сравнение с оригиналом, или определение ключевых слов по теме урока и выбор с их помощью видеоматериала на хостинге [1].

Эффективность комплексного использования электронных образовательных ресурсов, аудиовизуальных и технических средств обучения дисциплины в процессе организации самостоятельной и практической работы иностранных студентов в свете актуальности на сегодняшний день дистанционных форм обучения, доказывают в своих работах В.В. Вязовская, Т.А. Данилексая и М.Е. Трубчанинова [2], указывая на статистические данные увеличения объема языкового материала, усвоенного студентами с 10 до 35\%. Авторы приводят примеры использования в учебном процессе открытых онлайн-курсов для иностранцев при обучении русскому языку, реализуемые высшими учебными заведениями. По сути, это готовое электронное учебно-методическое обеспечение, включающее в себя информационные инструменты от теоретического учебного мультипрезентационного материала до промежуточной и итоговой аттестации. В качестве примера подобных онлайн-курсов, авторы приводят учебный портал Государственного института русского языка им. А.С. Пушкина «Образование на русском», включающий в себя комплексную предварительную диагностику для определения языкового уровня, образовательные тематические модули с лексическим и грамматическим наполнением, а также тестовые итоговые материалы. Кроме систематизированного учебного курса, иностранным студентам предлагаются авторские учебные материалы по чтению, пониманию и говорению на русском языке, которые построены по модульной системе и включают в содержание каждого занятия информационные ресурсы в форме онлайн-урока, направленные на аудиовизуализацию коммуникации преподавателя, обучающегося и других слушателей, в результате чего, обучение русскому языку как иностранному позволяет вывести уровень речевого взаимодействия из начальной условной сферы, ориентированной только на учебную ситуацию в сферу реальную, обусловленную ситуацией речевой коммуникации. Таким образом, подобные учебные порталы имеют эффективную возможность реализации не только аудиторных занятий в онлайн-режиме под руководством преподавателя, но и большие перспективы в организации самостоятельного обучения иностранных студентов оффлайн при прохождении различных общеобразовательных учебных программ на русском языке.

Таким образом, в сложившейся ситуации актуализации дистанционного образования и увеличением, в связи с этим, объема самостоятельной работы обучающихся, формат обучения русскому языку как иностранному с применением ИКТ технологий, онлайн-ресурсов и мультимедийных образовательных инструментов должен быть реализован посредством эффективной интеграции естественной и электронной сред обучения, т.к. начальный языковой уровень у обучающихся оставляет ряд требований, среди которых непосредственное учебной взаимодействие преподавателя и обучающихся видится нам как наиболее эффективная форма языковой коммуникации, в то время, как современные электронные образовательные ресурсы могут быть потенциально интегрированы в учебный процесс преподавания различных дисциплин с учетом их методической целесообразности, качеством содержательного учебного компонента, возможности реализации индивидуально-личностного подхода в процессе обучения, а также доступностью для использования на различных этапах овладения русским языком как иностранным.

\section{ЛИТЕРАТУРА}

1. Азимов Э.Г. Методика создания учебных материалов по русскому языку как иностранному с помощью цифровых видеозаписей / Э.Г. Азимов // Международная научно-практическая конференция «Электронные ресурсы открытого образования по русскому языку: лучшие практики»: сборник статей / отв. ред. В.Н. Климова. - М.: Гос. ИРЯ им. А.С. Пушкина, 2018. - С.11-15.

2. Вязовская В.В. Интернет-ресурсы в обучении русскому языку как иностранному: ожидания vs реальность / В.В. Вязовская, Т.А. Данилевская, М.Е. Трубчанинова // Russian Language Studies. - 2020. - №1. - C. 69-84.

3. Добринская Д.Е. Цифровое общество в социологической перспективе / Д.Е. Добринская // Вестник Московского университета. Серия 18: Социология и политология. - 2019. - Т. 25. - № 4. - С. 175-192. 
4. Лентовская А.В. Применение информационно-коммуникационных технологий в формировании коммуникативных навыков в иноязычной лингвокультуре / А.В. Лентовская // Вестник Московского университета. Серия 19: Социология и политология. - 2020. - Т.26. - №4. - С.76-88.

5. Пашаева К.Г. К вопросу обучения русскому языку как иностранному с помощью средств информационно-коммуникационных технологий / К.Г. Пашаева // Вестник Московского государственного областного университета. - 2017. - №3. - С.113-119.

6. Хромов C.C. E-learning как инструмент совместной когнитивной деятельности преподавателя и студентов при обучении русскому языку как иностранному / С.С. Хромов // Русистика и современность: старые вопросы, новые ответы. - 2017. - Т.2. - С. 611-618.

๔ Дышечева Марят Мухамедовна (dana2000_08@mail.ru), Токтоньязова Аида Эдуардовна (mgtu-teacher@mail.ru).

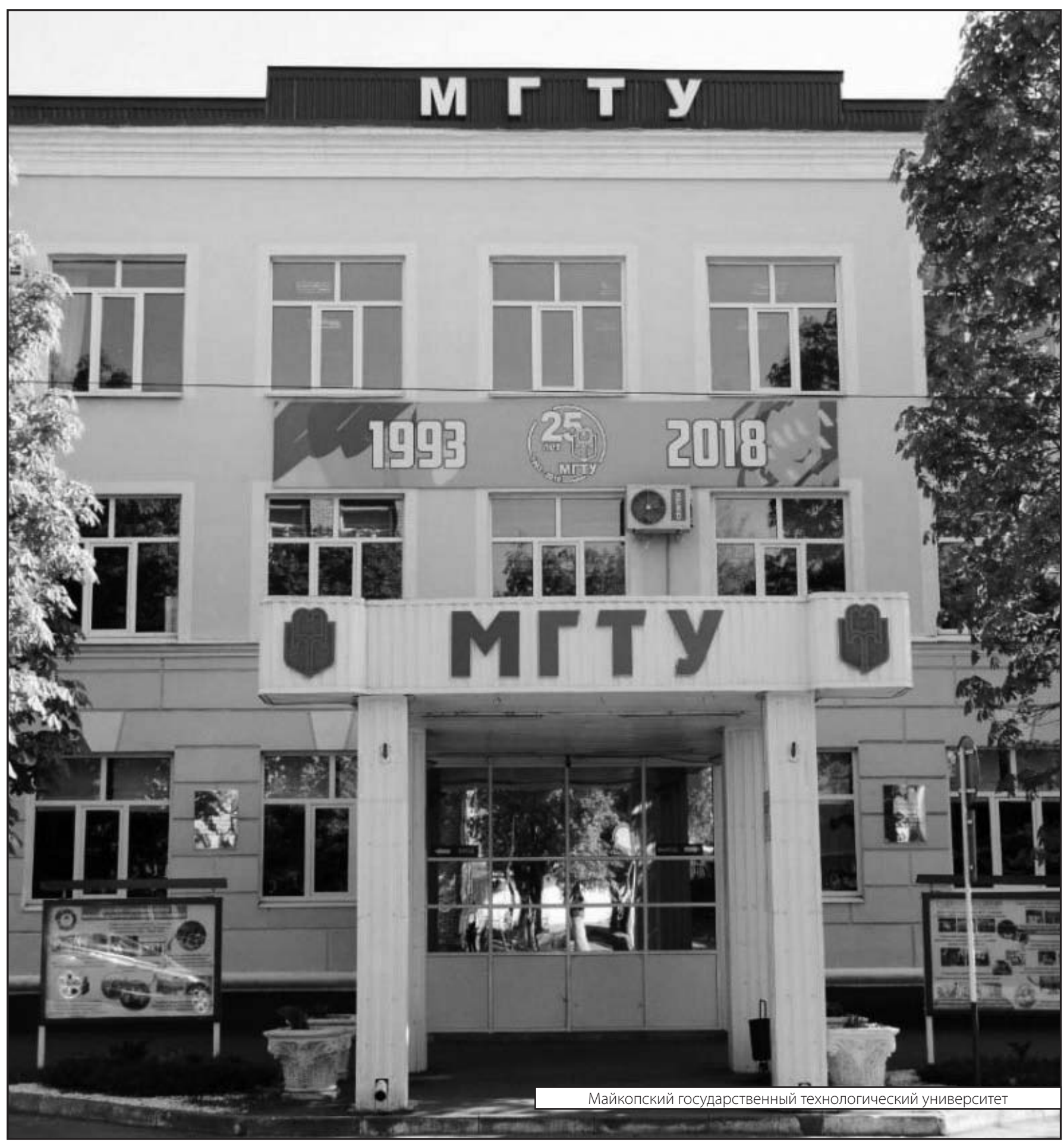

